\title{
A HISTÓRIA E A MEMÓRIA NA COMUNICAÇÃO ORGANIZACIONAL: UM ESTUDO DA NARRATIVA DA EXPERIÊNCIA PARA ATRATIVIDADE DOS PÚBLICOS
}

\author{
HISTORY AND MEMORY IN ORGANIZATIONAL COMMUNICATION: A STUDY \\ OF NARRATIVE OF THE EXPERIENCE FOR PUBLIC ATTRACTIVENESS
}
HISTORIA Y MEMORIA EN COMUNICACIÓN ORGANIZACIONAL: UN ESTUDIO DE LA NARRATIVA DE LA EXPERIENCIA PARA LA ATRACCIÓN DE LOS PÚBLICOS

\author{
Rodrigo Silveira Cogo ${ }^{1}$ \\ Mestrando em Ciências da Comunicação \\ Escola de Comunicações e Artes da Universidade de São Paulo \\ rodrigocogo@usp.br \\ Paulo Nassar ${ }^{2}$ \\ Professor-doutor do Departamento Relações Públicas, Propaganda e Turismo \\ Escola de Comunicações e Artes da Universidade de São Paulo \\ paulonassar@usp.br
}

\begin{abstract}
Resumo
É importante, para a comunicação nas e das organizações, encontrar uma sintonia com indivíduos e grupos de interação num tempo de multiprotagonismo. Este artigo postula que o resgate histórico, através da contação de histórias ou storytelling, conforma-se num formato atrativo e de repercussão, dando visibilidade à mensagem oficial mesmo na diversidade de fontes emissoras e de apelos retóricos. Para além da identificação de componentes estruturais, o texto também focaliza outras dimensões da construção narrativa, como sobre sua relação com a experiência humana.
\end{abstract}

Palavras-chave: Comunicação organizacional. Memória. Storytelling.

\begin{abstract}
It is important for organizational communication find a line with individuals and groups interact in a time of many protagonists. This article posits that the historical review, through storytelling, conforms to a format attractive and rebound, giving visibility to the official message that the diversity of sources and of rhetorical appeals. In addition to identifying structural components, the text also focuses on other aspects of narrative construction, and on its relation to human experience.
\end{abstract}

Key words: Organizational communication. Memory. Storytelling.

Esta obra está licenciada sob uma Licença Creative Commons 


\section{Resumen}

Es importante para la comunicación de las organizaciones, encontrar una línea con los individuos y grupos interactúan en un tiempo de multiprotagonismo. En este artículo se plantea que la revisión histórica, a través de historias, se ajusta a un formato atractivo y de rebote, dar visibilidad al mensaje oficial de que la diversidad de fuentes y de los recursos retóricos. Además de identificar los componentes estructurales, el texto también se centra en otros aspectos de la construcción narrativa, y en su relación con la experiencia humana.

Palabras clave: Comunicación organizacional. Memoria. Narración.

\section{INTRODUÇÃO}

O conceito de comunicação, caso se recorra à etimologia da palavra latina communis ou de outras com a mesma raiz, poderia ser dado como tornar comum, partilhar, comungar. Mas para que algo seja comum a um grupo, os envolvidos inevitavelmente têm de estar em relação. Mas isto não significa, todavia, que as percepções dos envolvidos tenham que ser as mesmas ou haver concordância com o que fora enunciado. Mais ainda não significa que as partes em contato de fato estejam intercambiando informação transformada em conhecimento, com qualquer nível de atenção ou retenção. É importante, para a comunicação nas e das organizações, encontrar uma sintonia com indivíduos e grupos de interação. O resgate histórico, através da contação de histórias ou storytelling, conforma-se num formato atrativo e de repercussão, dando visibilidade à mensagem oficial mesmo em tempos de diversidade de fontes emissoras.

A temática gira em torno da constatação de que emergem simultaneamente na sociedade atores diversificados e comunicantes, com alta potencialidade de criação, estimulados por plataformas conectadas facilitadoras de trocas e difusões de posicionamento. Com multiprotagonistas em interações mediadas ou incitadas pela tecnologia, a Comunicação Organizacional e as Relações Públicas acabam reconfiguradas para dar conta de expectativas mais elevadas em torno da transparência e da relevância das mensagens. Um centramento estratégico da narrativa, se localizado na memória organizacional como estimuladora de significados e geradora de pertencimentos, deve considerar a necessidade de recriação de formatos interativos como força atrativa diante da atenção pulverizada.

Este artigo trata de saber utilizar o lastro histórico não como acúmulo convencional de fatos, mas como encantamento do espírito e enriquecimento da experiência. A ideia é contribuir com questões e reflexões que levem a uma melhor compreensão das dimensões de interfaces da Comunicação nas e das organizações com ações de memória e dar início ao desenvolvimento de uma tipologia que possa fazer com que as organizações consigam 
consolidar o discurso institucional oficial como atrativo e gerador de conhecimento junto a públicos de interação.

\title{
2 CONSIDERAÇÕES SOBRE HISTÓRIA E MEMÓRIA
}

Como este estudo faz parte de reflexões de uma dissertação de mestrado que envolve o tema do storytelling, e sua variante especificamente oral, há uma firme escolha pelas questões da memória em detrimento da oficialidade da História - enquanto disciplina das Ciências Sociais. Por storytelling, entenda-se um formato de pensar a comunicação, baseado na contação de relatos de experiência de indivíduos integrantes de uma dada comunidade, com estrutura atrativa e engajadora.

A História busca produzir um conhecimento racional, uma análise crítica através de uma exposição lógica dos acontecimentos e vidas do passado, com prevalência documental. A memória, por sua vez, também é uma "construção do passado, mas pautada em emoções e vivências, ela é flexível e os eventos são lembrados à luz da experiência subsequente e das necessidades do presente" (FERREIRA, 2002, p.321). É baseada, portanto, nas evocações de pessoas sobre o passado - pessoal e ao mesmo tempo coletivo. Pinto traz uma importante contribuição, afirmando que

\begin{abstract}
a memória recupera a história vivida, história como experiência humana de uma temporalidade, e opõe-se à história como campo de produção de conhecimento, espaço de problematização e de crítica. Na operação histórica, o passado é tornado exclusivamente racional, destituído da aura de culto, metamorfoseado em conhecimentos, em representação, em reflexão; na constituição da memória, ao contrário, é possível reincorporar a ele, passado, um grau de sacro, de mito (PINTO, 2001, p.297).
\end{abstract}

A caracterização mais frequente da memória, segundo Meneses (1992, p.9), é de mecanismo de registro e retenção, depósito de informações, conhecimento e experiências, que também está suscetível a esquecimentos e ocultações. Borges (2007), no conto Funes, o Memorioso, marca o emblema da perda da condição humana pela saturação da memória e pela incapacidade de esquecer e, por conseguinte, de pensar, demonstrando a importância também dos mecanismos de seleção e descarte - que não são negativos em si mesmos. Todos os rastros da História, sejam do progresso ou da decadência, deixam registros na memória. Pinto (2001, p.294) resume muito bem: "tornamo-nos memoriosos e redefinimos, trilhando a fronteira porosa entre História e ficção, o lugar possível da memória. Memória pelos textos, pela constituição poética". Nora refere quase efusivamente a um conceito de memória: 
é a vida, sempre carregada por grupos vivos e, nesse sentido, ela está em permanente evolução, aberta à dialética da lembrança e do esquecimento, inconsciente de suas deformações sucessivas, vulnerável a todos os usos e manipulações, suscetível de longas latências e de repentinas revitalizações (NORA, 1993, p.9).

Pode-se definir memória como um conjunto de funções cerebrais que permitem ao homem guardar as mensagens, mas há que se levar em conta a permanente possibilidade de seleção destes conteúdos antes de sua evocação. É de fortes sentimentos e emoções que memórias diversificadas irrompem e invadem a cena pública, buscando reconhecimento, visibilidade e articulação. Em geral, suprem um espaço que a racionalidade história é impotente para exprimir, "atualizando no presente vivências remotas (revisitadas, silenciadas, recalcadas ou esquecidas) que se projetam em relação ao futuro" (SEIXAS, 2001, p.98).

Martin Kohli (apud MENESES, 1992, p.11) diz que a memória de grupos e coletividades se organiza, reorganiza, adquire estrutura e se refaz, num processo constante, de feição adaptativa. Ao contrário da noção de pacote de recordações, memória é um processo permanente de construção e reconstrução (BOSI, 1994, p.7). Para Ferreira (2004, p.98), memória é um elemento constitutivo do sentimento de identidade, tanto coletivo quanto individual, como fruto de um trabalho de construção constantemente negociada e representação de um fenômeno social. Velho (2001, p.11) reforça taxativo, afirmando que "não existe vida social sem memória, a própria possibilidade de interação depende de experiências e expectativas culturalmente compartilhadas". Para ele, não se trata de um único relato ou história, mas uma composição de discursos e representações das sociedades complexas, com versões que expressam a heterogeneidade dos atores. Por isto, é nesta relação entre a rede de significados e a dimensão da ação dos atores sociais que deve ser caracterizada a importância das memórias (VELHO, 2001, p.11).

Nora (1993, p.14) faz um apanhado muito instigante do que seriam vários tipos de memória. Para este cientista social francês, é preciso ter a consciência clara sobre a memória verdadeira, abrigada no gesto e no hábito, nos ofícios onde se transmitem os saberes do silêncio e do corpo; sobre a memória da impregnação com os saberes reflexos; e a memória transformada por sua passagem em história, por isto voluntária e deliberada, vivida como um dever. O filósofo francês Henri Bergson é citado por Nassar (2007, p.40) para dizer que "a imagem-lembrança, que vem espontaneamente à mente quando nossos sentidos esbarram em expressões organizacionais (arquitetura, marca, produto, empregado e outras) é a memóriapura". 


\subsection{Narrativas orais da experiência na contação de histórias}

Segundo Echeverría (2003, p.20), antes da invenção do alfabeto, os seres humanos viviam na "linguagem do vir-a-ser". A linguagem e a ação estavam unidas, as histórias narravam as ações dos atores e, desta maneira, aprendia-se. Contudo, o alfabeto separou o narrador da linguagem e da ação, e o surgimento do texto escrito produziu a mudança para a linguagem das ideias. A história geralmente se constitui a partir da narrativa linguística e é compreendida como fenômeno humano e social, que surge no processo de interação, no jogo coletivo de indivíduos que, juntos, coordenam ações (ECHEVERRÍA, 2003, p.362).

Os relatos nem sempre se referem à forma pela qual a história se desenrolou, mas como ela poderia ter ocorrido, portanto não incidem na realidade, mas sim na possibilidade. Portelli (1993, p.50) explica que, pondo em contraste o mundo desejável com o existente e reclamando que, só por acidente, aquilo não aconteceu, as hipóteses permitem ao narrador transcender a realidade como dada e recusar a se identificar e se satisfazer com a ordem existente. Os relatos são criações narrativas com espontaneidade. $\mathrm{O}$ passado narrado carrega sempre uma opinião, porque "a arte do narrar envolve a coordenação da alma, da voz, do olhar e das mãos" (FROCHTEGARTENN, 2005, p.372).

A narração é uma prática de linguagem e se renova a cada experiência de recordar, pensar e contar, porque "a narração avança e recua sobre a linha do tempo, como que transbordando a finitude espaço-temporal que é própria dos acontecimentos vividos" (BENJAMIN, 1986a, p.37). A narração doa um tempo e um lugar, uma sequência e uma causalidade às reminiscências. Como diz Schank (apud PEREIRA; VEIGA; RAPOSO; FUKS; DAVID; FILIPPO, 2009, p.101), "a mente pode ser vista como uma coleção de histórias, coleção de experiências já vividas".

Lucena Filho, Villegas e Oliveira (2008, online) atestam que as histórias acompanham as origens sociais do ser humano na tradição oral e escrita. Sempre que uma história é contada, fala dos atores e dos feitos em contexto particular e apresenta experiências que contribuem para a aprendizagem dos narradores, leitores ou ouvintes. Segundo o contexto no qual é criada/estruturada, a história pode gerar espaços de reflexão do passado e inspiração para a transformação do futuro. Para Terra ([s.d.], online), a humanidade vem contando histórias de forma ininterrupta desde que adquiriu a fala ou mesmo antes disso, desde que aprendeu a gesticular e se comunicar. De fato, muitos antropólogos dizem que é a capacidade 
de contar histórias que separou o homem de outros primatas ao longo da evolução. Barthes (1971) colabora com um conceito bastante preciso e simples, ao dizer que

a narrativa está presente em todos os lugares, em todas as sociedades; não há, em parte alguma, povo algum sem narrativa; todas as classes, todos os grupos humanos têm suas narrativas, e frequentemente estas narrativas são apreciadas por homens de cultura diferente [...] a narrativa está aí, com a vida (BARTHES, 1971, p.20).

A semiótica, ciência que estuda as estruturas linguísticas e as formas de comunicação, continua Terra ([s.d.], online), relata que o ser humano transmite quase 700 mil sinais físicos distintos, incluindo cerca de 1.000 posturas corporais, 5.000 tipos de gestos e 250.000 expressões faciais, dada sua capacidade natural de transmitir sinais, informações e conhecimento. Sobre isto, Benjamin (1986b, p.220-221) sentencia que a narração, em seu aspecto sensível, não é de modo algum o produto exclusivo da voz, e que, "na verdadeira narração, a mão intervém decisivamente, com seus gestos [...] que sustentam de cem maneiras o fluxo do que é dito". Ewald (2008, online) fala que, ao enfatizar a conexão entre narrar e lembrar, há uma exposição da "ligação intrínseca que há entre a memória, narrativa oral e ação social". A história é construída socialmente, através de uma interação, nos momentos de espacialização, por meio da voz, do corpo e das inscrições.

Segundo Christian Salmon (apud DOMINGOS, 2008c, p.95), autor de Storytelling : La machine à fabriquer des histoires et à formater les esprits, narrar é viver, ou seja, produzir um storytelling revival, onde as narrativas pertencem às grandes categorias de conhecimento das quais o homem se serve para compreender e ordenar o mundo.

Quando se fala de histórias, está-se dizendo que se inserem em um discurso histórico, em uma meta-história particular caracterizada pela coerência de uma comunidade que vive numa determinada linguagem. Assim, as histórias proporcionam aprendizado à medida que revelam estruturas de coerência nas quais estão incluídos o tempo e os feitos dos atores nele envolvidos (ECHEVERRÍA, 2003, p.363).

Postula-se que os relatos contenham uma atmosfera de mito. Vale dizer que, em grego antigo, os termos mythos e istoria tinham em comum o sentido do discurso ou narração, sendo que o primeiro traz noção de trama e conto e o segundo de interrogação e exame (PASSERINI, 1993, p.29). É sabido que Tucídides, ao conceituar a história, faz uma distinção clara entre uma ciência de análises cuidadosas e os mythódes, ou seja as tradições orais conectadas com o reino do fabuloso. Os mitos, diferentemente da história, são narrações que tentam exprimir dimensões divinas ou sobrenaturais no entremeio da abordagem racional, buscando ser mais agradáveis e utilizando um discurso que dispensa demonstração. Ora, "as 
histórias de vida podem ser vistas como construções de mito biografias singulares, usando opções de recursos diversos, que incluem mitos, combinando o novo e o antigo em expressões únicas" (PASSERINI, 1993, p.39).

Como assinala Eliade (2001, p.72), o tempo considerado sagrado e forte é o tempo da origem, da cosmogonia, da criação da realidade, que serve como inspiração permanente. Projetos de memória podem funcionar, portanto, como reatualizações rituais do tempo original e não meramente como comemoração festiva de acontecimentos passados. Os ritos e rituais são embasados exatamente nesta premissa de recitação, onde o regresso ao tempo de origem é simbolicamente nascer de novo e retomar energias, dado que "a vida não pode ser reparada, mas somente recriada pela repetição simbólica da cosmogonia” (ELIADE, 2001, p.74). Os participantes dos rituais tornam-se contemporâneos do acontecimento mítico retratado - saem do tempo histórico (constituído pela soma dos eventos profanos, pessoais e intrapessoais) e reúnem-se no tempo primordial e indestrutível. Nas festas, haveria uma experimentação da santidade da existência humana como criação divina, já que no resto do tempo há sempre o risco de esquecer-se do que é fundamental. Completa o autor:

o mito conta uma história sagrada, quer dizer, um acontecimento primordial que teve lugar no começo do tempo. Mas contar uma história sagrada equivale a revelar um mistério, pois as personagens do mito não são seres humanos: são deuses ou heróis civilizadores (ELIADE, 2001, p.84).

O mito é a história do que se passou na origem, a narração do que seres divinos fizeram, tornando-se verdade absoluta. A função mais importante do mito é, pois, 'fixar' os modelos exemplares de todos os ritos e de todas as atividades humanas significativas. Ele complementa:

tudo quanto os deuses ou os antepassados fizeram - portanto tudo o que os mitos contam a respeito da atividade criadora - pertence à esfera do sagrado [...] Em contrapartida, o que os homens fazem por própria iniciativa, o que fazem sem modelo mítico, pertence à esfera do profano: é uma atividade vã, ilusória, enfim, irreal (ELIADE, 2001, p.85)

É interessante registrar o conceito de mito em Lévi-Strauss (1970, p.140), para quem "é, ao mesmo tempo, uma estória contada e um esquema lógico que o homem cria para resolver problemas que se apresentam sob planos diferentes, integrando-os numa construção sistemática". A tentativa de estudar e interpretar o mito é importante para a compreensão do papel assumido pelo sistema simbólico, tanto como elemento integrador e definidor da identidade da empresa, como revelador dos mecanismos de poder. E neste panorama é que 
surgem os heróis, como legítimos portadores de uma verdade sobre o destino da empresa, sobre o perfil adequado de seus empregados e sobre os padrões de relações de trabalho desejados. São das histórias de atos de coragem, normalmente mitológicas, que nascem os heróis, que serão personificadores de valores e provedores de modelos de comportamento. Eles não têm existência a priori, mas vão sendo construídos e permitem até concessões dentro da rígida história oficial.

Falando sobre estudos de Robert McKee, Douek (2009) diz que storytelling é sobre arquétipos e não estereótipos:

enquanto as histórias estereotipadas ficam em casa e seus conflitos terminam em si mesmos, as histórias arquetípicas viajam os quatro cantos do mundo em diversas dimensões, fazendo o espectador viver uma realidade ficcional que ilustra o seu próprio dia-a-dia (DOUEK, 2009, p.39).

Um ponto relevante diz respeito à crescente demanda do grande público pela história vivida com a valorização das obras de history makers (FERREIRA, 2002, p.326). Essa denominação é atribuída para autores que escrevem sobre o passado sem fazer uso das regras estabelecidas pela comunidade acadêmica, ou que recolhem depoimentos orais carregando a crença de que o relato individual expressa em si mesmo a história.

Essa produção tem sido vista como mais atraente por apresentar uma narrativa de leitura ou de escuta mais agradável e de mais fácil compreensão. Afinal, como bem assinala Meneses (1992, p.16), o que o público deseja são lembranças de eventos que sejam "narráveis" e em que a contingência da materialidade seja compensada pela invenção da narrativa. Nisto, Nora (1993, p.20) também menciona como "retorno da narrativa" que se pode notar nas mais recentes maneiras de se escrever a história, assinala ele que "bem diferente da narrativa tradicional, fechada sobre si mesma".

Nassar (2009, p.303) visualiza que a comunicação tem primado pela objetividade e pelas mensagens de perfil quantitativo, notadamente ligada a funcionários, não havendo tempo para dialogar, fantasiar e para contar histórias. Isto é um paradoxo diante da constatação de que a subjetividade organizacional viabiliza a formação de uma cultura do sonho, da participação e da inovação, que são vitais para o atendimento de demandas sociais intangíveis e de legitimidade. Quanto trata de dimensões intangíveis, o pesquisador refere-se à reputação, à credibilidade, à confiança, que determinam a qualidade dos relacionamentos entre a organização, seus públicos e sociedade.

Para Domingos (2008b, online), "o storytellling é uma tentativa de humanização do espaço de interação". As narrativas tratam de assuntos diversos, como a vida dos grandes empreendimentos, ou mesmo narrativas ficcionais que possam servir para exemplificar um estado de espírito capaz de colocar toda uma empresa em interação comunicativa. O objetivo 
é formar uma atitude pragmática e viva, nas relações de trabalho, acrescido de forte valor não só intelectual, mas também ficcional. As personagens podem tornar-se suportes vivos de histórias vivas, onde se concretizam e encarnam ideias que, mesmo que complexas, podem se tornar acessíveis a todos por meio de um storytelling. As histórias fazem apelo a metáforas e metonímias, tendo por finalidade elucidar situações e tratar problemáticas complicadas. As metáforas desencadeiam ideias, ajudam a interpretar e ajustar, como meio de interação comunicativa eficaz para entrar em contato com um mundo que está além das palavras - "a vida que não pode ser dita, mas sim vivida" (DOMINGOS, 2008b, online). Não se trata, portanto, de qualquer narrativa de entretenimento, mas sim aquela que tem também o objetivo de formatar pensamentos e veicular significações. Este pesquisador complementa

são textos narrativos que produzem efeitos diretos nos grupos que as praticam, de modo invididual ou até mesmo global, nas dinâmicas de mudanças, de inovação, ou de clima relacional nas organizações e sociedades em rede. Produtos puros da imaginação, embora sempre baseadas nas experiências com o real (DOMINGOS, 2008b, online).

Aliás, o debate entre subjetividade e objetividade transformou-se numa oposição entre escrita literária e escrita cientificista. Haveria, segundo analisa Pollak (1992, p.210), de um lado o vazio, o seco, o enfadonho, que seria o discurso científico, ainda por cima reducionista e fechado à pluralidade do real, e de outro a história oral seria uma das possibilidades de reintroduzir nas ciências humanas, depois do período estruturalista, uma escrita não apenas subjetiva, mas sobretudo literária. Nas falas, o sociólogo austríaco identifica três tipos de estilo - cronológico, temático e factual. O predomínio no estilo cronológico está correlacionado com a característica de um grau mínimo de escolarização, no sentido de pensar em si próprio em termos de duração, de continuidade e situar-se em termos de início e fim. Já o estilo temático se liga pouco à cronologia e busca inspiração numa parte específica da trajetória do depoente, que embasa todas as rememorações, sendo uma elaboração mais intelectualizada. O estilo factual, por fim, é um relato completamente desordenado, típico de grau educacional baixíssimo (POLLAK, 1992, p.212).

\subsection{Processos de contar histórias organizacionais}

A partir da metade dos anos 90, os estudos discursivos da narrativa progressivamente abandonaram interesses básicos iniciais, como a identificação de componentes estruturais, para focalizar em outras dimensões da construção narrativa, como sobre a relação delas com a 
experiência humana e o que significa contá-las (BASTOS, 2004, p.119). De toda maneira, este item do presente estudo busca elucidar alguns parâmetros estruturais para a contação de histórias, ainda que dentro da noção de prática social, de atividade histórica e culturalmente situada.

Zanetti (2004, p.11) lembra que "a magia do ato de se contar uma história não se resume à história contada, mas ao próprio ato", reiterando que histórias transmitem segurança e conforto e trazem significados para a vida. As narrativas são eficientes meios de interação, pois comunicam, fornecem e transmitem informações. Esse ato está encontrando uma nova forma e novos objetivos na mídia tecnologizada. Não interessam mais só as qualidades do produto em si, como argumento para a venda, mas interessam também criar uma narrativa em que a trajetória da organização seja inspiradora e crie conexões que podem desencadear relações e, por conseguinte, amparar negócios. Contar histórias através de várias mídias é algo básico, essencial, simples e poderoso.

O ponto da narrativa é a sua razão de ser, além disto precisa ser contável, isto é fazer referência a algo extraordinário. A mensagem central e a reportabilidade são componentes que garantem a carga dramática e o clima emocional, onde o narrador utiliza recursos linguísticodiscursivos, conforme ensina Bastos (2004, p.120), como intensificadores lexicais (como uma briga muito feia), fonologia expressiva (alongar vogais, como uma briga mиииииiito feia; ou acelerar ou diminuir o ritmo da fala e aumentar ou abaixar o volume da voz), repetições (tipo uma briga тииииiito feia, mas тииииiito feia mesmo).

Taylor et al (apud BRUSAMOLIN; MORESI, 2008, p.48) investigaram por que algumas narrativas são mais efetivas que outras, sendo que a estética da história pode ser selecionada segundo os seguintes aspectos: sentimento de significado - a intuição do ouvinte tende a acreditar na história; conectividade - a história desperta ressonância no ouvinte, que viveu experiência semelhante; apreciada por si mesma - a história é agradável e por isso aceita pelos ouvintes, que reduzem seus filtros críticos e possíveis questionamentos.

Como destaca Poupinha (2007, p.700), nessas histórias que circulam, nas narrativas que se vão produzindo e reproduzindo consoante as lógicas próprias às relações sociais e às capacidades dos indivíduos em estruturar suas versões, os acontecimentos são narrados e os indivíduos são representados, assumindo o valor de personagens numa ação que se vai perpetuando no interior da organização. Para ele, a contação de histórias permite a estruturação das representações dos assuntos organizacionais em três níveis: a) uma zona de histórias estabelecidas, visíveis nos históricos da organização; b) uma zona de histórias em movimento, visíveis nos projetos e respectiva ação de comunicação da organização no momento presente; e c) uma zona de histórias potenciais, relativas a assuntos que façam parte 
da estratégia da organização e que impliquem tratamento futuro e ainda a assuntos que possam fazer parte ou que já tenham existido na trajetória narrada da organização - mas que em algumas das suas dimensões não façam parte do domínio público, tendo circulado em espaços privados de relação e conhecimento. Essa narratividade implica uma dramaturgia organizacional, no sentido em que compõe, através da memória, o quadro de autoapresentação da organização para conformação da reputação. Sunwolf (2005, p.312), sobre isto, complementa dizendo que ajudar as pessoas a notar seus papéis em uma história mais ampla "tira-as do foco estreito em si mesmas, estimulando-as gentilmente a se concentrar em suas comunidades e nas histórias tecidas e compartilhadas que as cercam".

As histórias possuem a capacidade de lidar bem com a complexidade: uma boa narrativa é dinâmica e desenvolve-se no imaginário de quem a ouve, conduzindo a um nível de compreensão por vezes até superior ao do narrador (BRUSAMOLIN; MORESI, 2008, p.40). Eles apresentam o triângulo da narrativa de histórias como composto por história, narrador e audiência num determinado contexto, elementos que têm a mesma preponderância.

É importante pensar nos modos de funcionamento cognitivo, que Jerome Bruner (1997, p.14) divide em lógico-científico (ou paradigmático) e narrativo. O primeiro busca gerar conhecimento com base na verificação da veracidade ou falseamento de hipóteses, adotando uma descrição e explicação formais e objetivadas do contexto que as geram. O modo narrativo, por sua vez, consiste em contar boas histórias, dramas envolventes, relatos críveis e trata de intenções e ações humanas e das vicissitudes das intenções humanas. A abordagem, neste segundo caso, concentra-se em compreender o particular, em buscar os significados que as pessoas constroem, baseando-se em suas histórias, sejam elas orais ou escritas.

Segundo Echeverría (2003, p.263), qualquer que seja o problema enfrentado por uma organização, este sempre poderá ser examinado em sua estrutura conversacional. Ele apresenta algumas tipologias de conversações: a) de orientação, conversas à base de declarações fundamentais sobre o futuro desejado da organização, princípios, valores, políticas nutridas pelas ações de diferentes equipes; b) de desenho, conversas à base de declarações sobre como se estrutura a organização, definição de processos, papéis e atribuições, especulação de futuro e conversações de estratégias; c) de implementação, conversações de compromissos, identificação de objetivos, pedidos, ofertas, negociação e implementação das ações, assim como a abertura de maiores redes de colaboração e soluções de problemas; e d) de aprendizagem, conversações de avaliação, na qual surgem as perguntas sobre como se está estruturando a organização sobre o próprio fluxo conversacional e a rede de relacionamentos que a constitui. A partir do correto manuseio destas tipologias, uma 
narrativa pode ser fraca, sem impacto no contexto, ou poderosa quando faz sentido para outros gerando consequências, significados, mundos e novas possibilidades de ação, enriquecendo a compreensão dos fenômenos. O empoderamento da narrativa acontece ainda quando o público-alvo pode tornar-se uma espécie de coautor, ao ser consultado de antemão sobre o enredo a ser desenvolvido; ou ser atuante na trama narrada em tempo real, quando, então, ele vive a trama, enquanto ela se desenrola (DOMINGOS, 2008a, online). Por trama, Micoczky e Imasato definem com simplicidade: "é a maneira como se decide ordenar a narrativa", inclusive com esquecimentos que buscam, com o silenciar, dar ênfase a outras partes da história. Alguns autores (Rhodes, 2000, 2001; Czarniawska, 1999; Boje, Luhman e Baack, 1999 apud MICOCZKY; IMASATO, 2005, p.84), consideram que esses silêncios são muito importantes para a criação das narrativas, já que tão importante quanto entender a trama é considerar o que é esquecido.

Uma história não é um texto comum, sendo formada por elementos estruturais particulares, como se vê no estudo de Migon e Silva Junior (2007, online) sobre Group Storytelling como técnica de utilização de histórias em grupos de pessoas como método de comunicação para compartilhamento de conhecimento. Estes elementos são a divisão em eventos, a causalidade, o início, meio e fim, uso de personagens e linguagem única. Cada história precisa ser analisada sob o ponto de vista de sua aplicação para cada situação, tempo disponível e público. Os autores retomam a questão dos participantes colaborem na trama, significando ajudar também na identificação de possíveis problemas no ambiente de trabalho - que podem ou não ser reais e apontam gargalos pequenos ou críticos, redundâncias, exceções, atalhos, excessos, falta de informação.

Para Terra ([s.d.], online) histórias importantes têm algumas características que as distinguem. Elas marcam eventos importantes ou que foram destacados como importantes pelos líderes da organização, incluindo tramas, desafios ou mesmo pequenos incidentes carregados de significado. As histórias precisa fazer sentido em qualquer época, com pontos altos e desfechos marcantes ou mesmo inesperados. São curtas, com propósito e carregadas de analogias, metáforas e visões de mundo. Para ele, histórias de impacto contam invariavelmente com personagens que carregam em suas ações muito simbolismo. Alguns destes personagens viram mitos e, ao longo do tempo, suas ações, ao serem recontadas, vão se distanciando da realidade efetiva - o que tende a perdurar são as lições, valores, dilemas e posicionamentos morais ou éticos dos personagens. E complementa, afirmando que "a experiência, as lições aprendidas e o contexto são transmitidos de forma a estabelecer um significado, uma emoção e servir como padrão ou arquétipo para tomada de decisão ou ação futura" (TERRA, [s.d.], online). 
As histórias precisam favorecer o onírico, o fantasioso e espetacular, com predomínio do emocional sobre o lógico, permitindo diálogos e informações mais humanizados entre as pessoas. Assim, o storytelling permite que tanto o sujeito narrador como seu receptor sejam conduzidos a um ambiente praticamente sem censura ou crítica (DOMINGOS, 2008c, p.101). Sunwolf (2005, p.307) afirma que histórias orais podem ser "recurso ímpar para alimentar o espírito, pois produzem impacto emocional. Um conto poderoso é sempre fundamentado não na trama, mas na emoção, que a oralidade da narrativa destaca". De, todo modo, histórias têm apelo muito grande em virtude de seus temas e personagens. Os temas tendem a ser muito abrangentes e incluem arrependimento, perdão, ressurreição, necessidade de justiça social, com aspectos temáticos como certo e errado, sofrimento, amizade e imortalidade. E não fogem do ciclo de vida com fases próprias de nascimento, crescimento, emergência, queda, dormência, numa relação com a escala de seu impacto social (POUPINHA, 2007, p.700).

Os contadores de histórias frequentemente falam 'eu' ou 'nós' para dar sentido ao contado e aproximá-lo das pessoas, com palavras vívidas em toda a narrativa a fim de retratar detalhes cênicos (SUNWOLF, 2005, p.308). As fábulas são narrativas curtas, que dependem quase exclusivamente do uso de animais como personagens, mas também são usadas porque focam atenção no comportamento e nos dilemas universais da vida em vez de em determinadas pessoas e seus feitos. Como um conto de sabedoria, a fábula relaciona-se ao provérbio, embora possa ter uma trama maior - alguns se referem a ela como provérbios estendidos. Já as parábolas, outra forma de estrutura de histórias, vêm sendo usadas como recurso popular para contar histórias espirituais (SUNWOLF, 2005, p.309).

Há visões que indicam que performances de contadores de histórias contêm muitas das condições necessárias para induzir transes, aqui entendidos como estado de consciência voltado para dentro da pessoa, de tal forma que os olhos dos ouvintes possam estar no contador, porém suas consciências estão voltadas para dentro delas mesmas. É o que Benson (apud SUNWOLF, 2005, p.311) fala sobre "resposta relaxante", quando os ouvintes encontram-se relaxados, abertos para uma retenção mais ativa daquilo que está sendo dito e ficam menos defensivos. Uma boa narrativa é aquela que podemos aceitar ou rejeitar e, paradoxalmente, tal liberdade torna mais provável a aceitação.

Pozzer (2005, p.40) concentra suas pesquisas em três linhas: geração, interação e visualização de histórias. A Geração refere-se à forma como a história é gerada, ou seja, como se dá a criação da estrutura que vai guiar aspectos mais gerais, como personagens, objetos e relacionamentos. A Interação (direcionamento) procura estabelecer como se dá a interação entre usuário, história (enredo) e personagens. Também é responsável pelo gerenciamento das ações dos personagens autônomos (agentes) de modo a manter a história coerente. Por fim, a 
Exibição trata a forma de representação visual da história, a transformação das abstrações das estruturas internas das personagens em ações realistas dentro de um espaço. A ideia é contar histórias que motivem e inspirem os envolvidos, com uso de linguagens mais cotidianas e narrativas que, em geral, despertem o interesse, criando entretenimento.

Sunwolf (2005, p.313) apresenta o "modelo de cinco funções de histórias orais para contadores e ouvintes", que sugere que contos narrados e ouvidos dentro de vários contextos podem funcionar como: a) Ponte: uma maneira de conectar diferentes pessoas (narrativas relacionais); b) Sementes: um modo de aprender (narrativas pedagógicas); c) Ferramentas: uma forma de criar narrativas heurísticas); d) Álbum de recordações: um jeito de lembrar (narrativas históricas); ou e) Visionário: um meio de visualizar o futuro (narrativas visionárias). Vale referir que o modo interpessoal de contar histórias, frente a frente, ajuda os contadores e suas audiências a construir o próprio 'eu', a realidade, a achar o sentido de eventos vividos, a compartilhar conhecimento ou a influenciar valores, crenças e ações uns dos outros. O autor complementa defendendo que uma linguagem vívida traz credibilidade, “deflagra a atenção e tem poder de adesão. A linguagem falada, de fato, sempre cria um efeito mais intenso no ouvinte do que a linguagem escrita recitada. O ritmo, as pausas, as frases, tudo é diferente" (SUNWOLF, 2005, p.321).

Ainda é preciso mencionar que, após a seleção de histórias a serem narradas, deve ser programada um agendamento para cada uma delas, no qual constem itens como data prevista, local onde acontecerá, instalação de equipamentos, especificação das pessoas que devem estar presentes e definição do narrador (BRUSAMOLIN; MORESI, 2008, p.48). O ato de contar histórias, o ritual e os símbolos são os principais meios através dos quais os integrantes de um grupo ligam-se uns aos outros. Se expandir o pensamento para além dos púlpitos, os gestores verão espaços mais ricos para a prática e a partilha de contos e histórias. Por isto, para além do formato da contação de histórias, é preciso centrar atenção nos indivíduos narradores. Alguns são naturalmente excelentes contadores, mas, como aconselha Terra ([s.d.], online), se storytelling passar a fazer parte do arsenal de ferramentas gerenciais estratégicas, gestores e líderes precisarão ser treinados para incorporar habilidades para contar ou escrever boas histórias. Conforme analisam Brusamolin e Moresi (2008, p.41), quando o gestor conta uma história, constrói uma camaradagem com a equipe por meio do compartilhamento de sua experiência, o que conduz a percepções de confiança.

Busatto (2005, p.26) afirma que o contador de histórias do século XXI apresenta seu trabalho por meio de espetáculos de narração oral, performances artísticas elaboradas, com o domínio de técnicas corporais e vocais e critérios de seleção para escolha de histórias. Performance é a vida dada ao texto pelo narrador, por meio de sua voz. Ou, ainda, "um ato de 
comunicação que se distingue de outros atos da fala, principalmente por sua função expressiva e poética" (BUSATTO, 2005, p.26). Entre as possibilidades, estaria o uso de música, dança, poesia, declamação, mímica e artes plásticas. Todavia, para o ambiente organizacional, vale dizer que o ato de narrar a história deve ser conduzido de forma natural. Não convém a uma história organizacional que o narrador faça uma performance, modificando seu tom de voz e comportamento usual. A narrativa deve ter credibilidade e, para tanto, os gestos devem ser verdadeiros. Neste caso, vale a posição de Shedlock (2004, p.23) de que "contar histórias é a arte de esconder a arte".

\section{CONSIDERAÇÕES}

À medida que for sendo construída uma ponte entre os conceitos de memória organizacional e de storytelling, poderemos alcançar um formato narrativo que se constitua atrativo para os públicos. As histórias que as pessoas contam sobre as relações sociais nas organizações precisam ser tratadas como narrativas que buscam construir sentido para as ações, tanto passadas como futuras, procurando plausibilidade para as experiências. Ricas em detalhes, as narrações possibilitaram o resgate das opiniões, sentimentos e intenções por trás das ações realizadas.

Esta profundidade e complexidade, porém, parecem passar despercebidas num cotidiano profissional de comunicadores organizacionais e relações públicas ainda absortos no atendimento pontual e sequencial de demandas de setores, o que dificulta a reflexão sobre a extensão dos atos retóricos em ambiente de trabalho e/ou em nome de empreendimentos e negociações multipúblicos. A visão mecânica ou instrumental ainda parece predominar na área, como se estivesse tratando do simples manuseio, mais ou menos estratégico, de produção e distribuição de mídias de contato. Na verdade, esta concepção está absolutamente em questionamento numa sociedade cada vez mais em rede, consciente do poder da inteligência coletiva e da potencialidade da internet no descentramento da fonte emissora. Com pessoas alterando de maneira significativa o foco de suas atribuições de confiabilidade, suprimindo ou atenuando a pretensa influência das grandes corporações, dos governos, das igrejas ou da mídia broadcast, cria-se uma outra ordem de parâmetros para conformar a reputação. Entre os desafios da comunicação nas e das organizações, cresce a importância da conquista da atenção dos interlocutores, para só então buscar a transformação da informação em conhecimento, a mobilização para agir ou mudar e ainda a recomendação, ou mesmo defesa, do negócio, seus produtos, serviços e pontos de vista. 
Buscou-se afirmar que as reminiscências sobre o percurso histórico de uma organização, destituídas de qualquer obrigatoriedade factual e sucumbência hierárquica e valorizadoras de todas as vozes, constituem um forte argumento para os discursos oficiais nesta arena de alta concorrência de significados e protagonismos. $\mathrm{O}$ excesso de objetividade em todas as interfaces oficiais, por obra da supremacia da performance quantitativa e do lucro exclusivamente financeiro, precisa ser revisto não só do prisma comunicacional, mas também de gestão. Assim, seria possível a emergência de um ambiente receptivo à expressão e consideração das subjetividades e à estruturação de narrativas diferenciadas das falas rígidas e manualizadas facilmente encontradas em reuniões, sites, folhetos, entrevistas ou boletins informativos - cuja atratividade e efetiva escuta e leitura são cada vez menores e portanto menos relevantes e memoráveis.

\section{REFERÊNCIAS}

BARTHES, Roland. Aula. São Paulo: Cultrix, 1971.

BASTOS, Liliana Cabral. Narrativa e vida cotidiana. Scripta, Belo Horizonte: Programa de Pós-graduação em Letras da PUC-MG, v.7, n.14, p.118-127, 1.sem.2004.

BENJAMIN, Walter. A imagem de Proust. In: BENJAMIN, Walter. Obras escolhidas. $2^{\mathrm{a}}$.ed. São Paulo: Brasiliense, 1986a, p.36-49.

BENJAMIN, Walter. O narrador: considerações sobre a obra de Nikolai Leskov. In: BENJAMIN, Walter. Obras escolhidas. 2ª .ed. São Paulo: Brasiliense, 1986b, p.197-221.

BORGES, Jorge Luis. Ficções. São Paulo: Companhia das Letras, 2007.

BOSI, Ecléa. Memória e sociedade: lembrança de velhos. 3.ed. São Paulo: Companhia das Letras, 1994.

BRUNER, Jerome. Realidade mental, mundos possíveis. Porto Alegre: Artes Médicas, 1997.

BRUSAMOLIN, Valério; MORESI, Eduardo. Narrativas de histórias: um estudo preliminar na gestão de projetos de tecnologia da informação. Ciência da Informação. Brasília, vol.37, n.1, p.37-52, jan./abr. 2008. Disponível em:

<http://revista.ibict.br/index.php/ciinf/article/viewArticle/1005>. Acesso em: 3 fev. 2010.

BUSATTO, Cleomari. Narrando histórias no século XXI: tradição e ciberespaço. 2005. 132 f. Dissertação (Mestrado em Literatura) - Universidade Federal de Santa Catarina, Florianópolis. 2005. Disponível em: <http://www.tede.ufsc.br/teses/PLIT0195.pdf >. Acesso em: 22 mai.2010.

DOUEK, Marcelo. Planejamento de marca e roteiros de cinema. Meio\&Mensagem. São Paulo, n.1367, p.39, 13 jul 2009. 
DOMINGOS, Adenil Alfeu. Storytelling: narrativas midiadas como fenômeno de comunicação institucional. Jornada de Ciências da Saúde e Jornada de Ciências Sociais Aplicadas, III, 2008, Bauru, SP. Anais... Bauru, SP: Faculdades Integradas de Bauru, 2008a. Disponível em: <http://www.fibbauru.br/files/Storytelling$\%$ 20narrativas $\% 20$ mediadas $\% 20$ como $\% 20$ fen $\%$ C3\%B4meno $\% 20 \mathrm{de} \% 20$ comunica $\% \mathrm{C} 3 \% \mathrm{~A} 7$ $\% \mathrm{C} 3 \%$ A3o\%20institucional.pdf>. Acesso em: 15 abr.2010.

DOMINGOS, Adenil Alfeu. Storytelling e Mídia: a narração de histórias construindo o poder político. In: Encontro da União Latina de Economia Política da Informação, da Comunicação e da Cultura, II, 2008, Bauru, SP. Digitalização e Sociedade. Bauru,SP: Unesp, 2008b. Disponível em:

<http://www.faac.unesp.br/pesquisa/lecotec/eventos/ulepicc2008/anais/2008_Ulepicc_03920409.pdf>. Acesso em: 15 abr.2010.

DOMINGOS, Adenil Alfeu. Storytelling: fenômeno da era da liquidez. Signum: Estudos da Linguagem. Londrina: Universidade Estadual de Londrina. v.11, n.1, p.93-109, jul.2008c.

ECHEVERRÍA, Rafael. Ontología del lenguaje. 6a. ed. Santiago, Chile: J.C.Saéz, 2003.

ELIADE, Mircea. O sagrado e o profano: a essência das religiões. São Paulo: Martins Fontes, 2001.

EWALD, Felipe Grüne. Memória e narrative: Walter Benjamin, nostalgia e movência. Nau Literária. Porto Alegre: Revista Eletrônica do Programa de Pós-Graduação em Letras da UFRGS. vol.4, n.2, jul./dez. 2008. Disponível em: <http://www.seer.ufrgs.br/index.php/NauLiteraria/article/view/5994>. Acesso em: 14 mai. 2010 .

FERREIRA, Marieta de Moraes. História, tempo presente e história oral. Topoi, Rio de Janeiro, dez.2002, p.314-332.

FERREIRA, Marieta de Moraes. Memórias da história. Nossa História. Ano 1. n.8. São Paulo: Vera Cruz/Biblioteca Nacional, jun.2004, p.98.

FROCHTENGARTEN, Fernando. A memória oral no mundo contemporâneo. Estudos Avançados, São Paulo: Revista do Instituto de Psicologia da USP, v.19. n.55. p.367-376. set./dez. 2005.

LÉVI-STRAUSS, Claude (Org.). Mito e linguagem social: ensaios de Antropologia Estrutural. Rio de Janeiro: Tempo Brasileiro, 1970.

LUCENA FILHO, Gentil; VILLEGAS, Margarita Maria; OLIVEIRA, Sheila. Histórias de aprendizagem e gestão organizacional: uma abordagem antológica e hermenêutica. Ciência da Informação. Brasília, vol.37, n.2. mar./ago. 2008. Disponível em:

$<$ http://revista.ibict.br/index.php/ciinf/article/viewArticle/1063>. Acesso em: 21 mai.2010.

MENESES, Ulpiano Bezerra de. A história, cativa da memória? Revista do Instituto de Estudos Brasileiros, São Paulo, n.34, 1992, p.9-24.

MICOCZKY; Maria Ceci; IMASATO, Takeyoshi. Narrativas e histórias nos estudos organizacionais: um diálogo sobre referências e práticas. Economia \& Gestão. Belo 
Horizonte: Instituto de Ciências Econômicas e Gerenciais da PUC-MG, v.5, n.11, p.77-96, dez. 2005.

MIGON, Lilian; SILVA JUNIOR, Luiz Carlos. De histórias a processos: utilização da técnica de Group Storytelling para apoio à elicitação de processos de negócios. In: Brazilian Workshop on Business Process Management, I, 2007, Gramado, RS. Knowledge discovery in business process. Porto Alegre: Editora da Universidade Federal do Rio Grande do Sul, 2007. Disponível em: <http://www.ic.unicamp.br/ beatriz/wbpm2007/35314.pdf>. Acesso em: 3 mai.2010.

NASSAR, Paulo. Memória e esquecimento. Revista Imprensa. São Paulo, n.222. p.40, abr. 2007.

NASSAR, Paulo. História e memória organizacional como interfaces das relações públicas. In: KUNSCH, Margarida M. Krohling (Org.). Relações Públicas - história, teorias e estratégias nas organizações contemporâneas. São Paulo: Saraiva, 2009. p.291-306.

NORA, Pierre. Entre memória e história: a problemática dos lugares. Trad. Yara Khoury. Projeto História, São Paulo: Revista do Programa de Estudos Pós-Graduados em História e do Departamento de História da PUC/SP, n.10, p.7-28, dez. 1993.

PASSERINI, Luisa. Mitobiografia em história oral. Projeto História, São Paulo: Revista do Programa de Estudos Pós-Graduados em História e do Departamento de História da PUC/SP, n.10, p.29-40, dez. 1993.

PEREIRA, Andréia; VEIGA, Kátia; RAPOSO, Alberto; FUKS, Hugo; DAVID, Viviane; FILIPPO, Denise. Storytelling imersivo colaborativo: Time2Play no Second Life. Simpósio Brasileiro de Sistemas Colaborativos, VI, 2009. Fortaleza. Anais... Fortaleza: Ed. IEEE-CS. out. 2009. p.99-105. Disponível em: <http://groupware.les.inf.puc-

rio.br/groupware/publicacoes/SBSC09_Time2Play_Final1.pdf>. Acesso em: 20 abr. 2010.

PINTO, Júlio Pimentel. Todos os passados criados pela memória. In: LEIBING, Annette; BENNINGHOFF-LÜHL, Sibylle (Orgs.). Devorando o tempo: Brasil, o país sem memória. São Paulo: Mandarim, 2001. p.293-300.

POLLAK, Michael. Memória e identidade social. Estudos Históricos, Rio de Janeiro, vol.5, n.10, p.200-212, 1992.

PORTELLI, Alessandro. Sonhos ucrônicos - memórias e possíveis mundos dos trabalhadores. Projeto História, São Paulo: Revista do Programa de Estudos Pós-Graduados em História e do Departamento de História da PUC/SP, n.10, p.41-58, dez. 1993.

POUPINHA, Luís Miguel. Comunicação estratégica: Aplicação das ideias de dramaturgia, tempo e narrativas. In: FIDALGO, António; SERRA, Paulo (Orgs.). Actas volume IV Campos da Comunicação. 2007, p.699-703.

POZZER, Cezar Tadeu. Um sistema para geração, interação e visualização 3D de histórias para TV interativa. 2005. 157 f. Tese (Doutorado em Informática) - Pontifícia Universidade Católica do Rio de Janeiro, Rio de Janeiro. 2005. Disponível em: <http://wwwusr.inf.ufsm.br/ pozzer/arquivos/pozzer_tese_2005.pdf>. Acesso em: 22 mai.2010. 
SEIXAS, Jacy Alves de. Percursos de memórias em terra de história: problemáticas atuais. In: BRESCIANI, S.; NAXARA, M. (Orgs.). Memória e (res)sentimento. Campinas: Unicamp, 2001.

SHEDLOCK, Marie. Da introdução de A arte de contar histórias. In: GIRARDELLO, Gilka (Org.). Baús e chaves da narração de histórias. Florianópolis: SESC, 2004.

SUNWOLF, J. Era uma vez, para a alma: uma revisão dos efeitos do storytelling nas tradições religiosas. Comunicação \& Educação. São Paulo: Revista do Curso de Especialização em Gestão da Comunicação da Escola de Comunicações e Artes da USP, a.10, n.3, p.305-325, set./dez. 2005.

TERRA, José Cláudio. Storytelling como ferramenta de gestão. In: Biblioteca Terra Fórum. São Paulo, [s.d.]. Disponível em:

<http://www.terraforum.com.br/biblioteca/Documents/Storytelling\%20como\%20ferramenta $\% 20$ de $\% 20$ gest\%C3\%A3o.pdf $>$. Acesso em: 21 mai.2010.

VELHO, Gilberto. Memória, cultura e sociedade. In: LEIBING, Annette; BENNINGHOFFLÜHL, Sibylle (Orgs.). Devorando o tempo: Brasil, o país sem memória. São Paulo:

Mandarim, 2001. p.11.

ZANETTI, Elói. Pai me conta uma história. Gazeta do Povo, Curitiba, 9 ago. 2004, Opinião, p.11.

Original recebido em: 18/05/2011

Aceito para publicação em: 12/09/11

Resumo sobre os autores:

${ }^{1}$ Rodrigo Silveira Cogo é profissional de Relações Públicas, graduado pela Universidade Federal de Santa Maria (1994), com especialização em Gestão Estratégica em Comunicação Organizacional e Relações Públicas pela ECA/USP (2010), onde atualmente cursa Mestrado em Ciências da Comunicação, como pesquisador-bolsista do CNPq no tema memória organizacional e storytelling. É analista de pesquisa qualitativa da Ideafix Estudos Institucionais, de São Paulo(SP) e professor da Aberje.

http://buscatextual.cnpq.br/buscatextual/visualizacv.do?id=K4461569A4

\footnotetext{
2 Paulo Nassar é jornalista, graduado pela Pontifícia Universidade Católica de São Paulo (1982), com mestrado (2001) e doutorado (2006) pela Escola de Comunicações e Artes, da Universidade de São Paulo - onde atua como professor doutor no Departamento de Relações Públicas, Propaganda e Turismo e como professor e orientador no Programa de Pós-Graduação em Ciências da Comunicação. É diretor geral da Aberje. http://buscatextual.cnpq.br/buscatextual/visualizacv.do?id=K4757309U0
} 